Roger Williams University

DOCS@RWU

$12-8-2007$

\title{
Warts and all: using student portfolio outcomes to facilitate a faculty development workshop
}

Glenna M. Andrade

Roger Williams University, gandrade8474@outlook.com

Follow this and additional works at: https://docs.rwu.edu/fcas_fp

Part of the Arts and Humanities Commons

\section{Recommended Citation}

Andrade, Glenna M. 2007. "Warts and all: using student portfolio outcomes to facilitate a faculty development workshop." Assessing Writing 12 (3): 199-21

This Article is brought to you for free and open access by the Arts and Sciences at DOCS@RWU. It has been accepted for inclusion in Arts \& Sciences Faculty Publications by an authorized administrator of DOCS@RWU. For more information, please contact mwu@rwu.edu. 
ScienceDirect - Assessing Writing : Warts and all: Using student portfolio outcomes to facilitate a faculty development workshop

Assessing Writing

Volume 12, Issue 3, 2007, Pages 199-21

doi: 10.1016/j.asw.2008.02.002

Copyright $\odot 2008$ Elsevier Inc. All rights reserved.

Warts and all: Using student portfolio outcomes to facilitate a faculty development workshop

Glenna Andrade, Roger Williams University, Department of Writing Studies, SE 127, One Old Ferry

Road, Bristol, RI, 02890, USA

Available online 2 April 2008.

Abstract

In 2004, the Department of Writing Studies at Roger Williams University in

Bristol, Rhode Island, the U.S., began an assessment of student outcomes for two first-year writing courses (Fall 04 to Fall 05) to evaluate performance on previously established criteria. A study of the students' Portfolio Assessment Sheets concluded that one pervasive problem was "Development" as determined partly by low A grades in the two courses. To engage the faculty (full-time and adjunct), the grades from Fall 04, Spring 05, and Fall 05 were presented during a Summer Workshop in June 2006. After analyzing a sample student essay, the 28 faculty participants discussed the implications of "Development" and evaluated the presentation itself. This case study of one college's participatory exercise in improving writing found some faculty resistance and some unintended results. Keywords: Writing assessment; Portfolios; Student outcomes; Adjunct faculty 
development; Faculty workshop; Critical thinking

Article Outline

1. Background to the study

2. Literature review

3. Our purposes and goals

4. The workshop methods

4. 1. Phase 1: Understanding the data

4.2. Phase 1: Faculty discussion of the data

4.3. Phase 2: The focus on development

4.4. Phase 2: Engaging faculty to help a student develop the essay

4.5. Phase 3: Asking for feedback

5. Discussion

6. Conclusion

Appendix A. RWU Writing Studies Department's Course Guide Descriptions and Objectives

A. 1. Introduction to Academic Writing: WTNG 100

Course description

Course objectives

A.2. Expository Writing: WTNG 102

Course description

Course objectives

Appendix B. Weights of Student Outcome Criteria from RWU's Portfolio

Assessment Sheets

Appendix C. Weights of "Development" from Portfolio Assessment Sheet

Appendix D. Selected Faculty Responses to "Development" Workshop (June 14, 
2006) Faculty comments on assessment and presentation

References

1. Background to the study

Roger Williams University (RWU) is a small, liberal arts university that serves about 3500 undergraduates in the Northeast of the United States. For the last several years, The Writing Studies Program at RWU has used several measures for placement, evaluation, and grading during each semester. During Fall 04 and Fall 05, students were guided into two courses based on their score in the verbal portion of the Scholastic Aptitude Test (SAT.V). Those achieving a score of below 510 entered the WTNG 100 (Introduction to Academic Writing) course while those obtaining 510 and above entered the WTNG 102 (Expository Writing) course; moreover, an in-class, first-week diagnostic essay based on a prior reading confirmed placement. At the end of the semester in accord with a process-oriented approach and with programmatic guidelines, students from both courses composed a final portfolio of 3-4 selections, including an original, self-evaluative cover letter, 2-3 essay revisions of the students' choosing, and one new, ungraded essay on the topic of the instructor's choice. Most instructors consulted with students individually about revising their portfolio selections prior to final submission. The final portfolio grade was determined holistically by instructors' use of a Portfolio Assessment Sheet (PAS) that was scaled with percents awarded to several different criteria applicable to each course. Grades ranged from A, B, C, and C- to NP (Not Passing). For the students, the final portfolio grade was high-stakes because it contributed to $40 \%$ of the course grade.

The student outcomes for WTNG 100 and for WTNG 102 were developed during 
participatory faculty workshops in the late 1990s under the direction of Dr. Kate Mele, the then Writing Program Coordinator. Currently, the same program descriptions and objectives (see Appendix A) are distributed prior to each semester to the approximately 30-35 writing faculty members, of whom about $70-80 \%$ are contingently employed, and of these about $80 \%$ have worked for RWU for more than 2 years. Nearly all the faculty members teach both WTNG 100 and 102 in various semesters. Seven tenured and tenure-track Ph.D. faculty members have had education in Composition or Rhetoric, in contrast, the part-time faculty generally have an MA degree in English or a Master of Fine Arts (MFA) degree, yet they all offer an earnest commitment to improving instructions and student performance. Most instructors attend a Fall Orientation that reviews the program objectives and the PAS. Often, these same student outcomes and sample assignments are discussed during a Summer Workshop at the end of the spring semester. In these ways, the PAS maintain the Writing Studies Department's goal to "support the mission of the University by developing student's abilities to articulate critical analyses and sound arguments...(through) appropriate performance-based standards" (Roger Williams University, Department of Writing Studies, 2005). Moreover, the Writing Studies Department's analyses of student outcomes serve to establish programmatic consistency and to facilitate faculty development among both full- and part-time instructors. With these goals in mind, I began analyzing the scores on the PAS for WTNG 100 and 102 when appointed Chairperson of Writing Studies in 2004. By the end of the spring semester in 2006, I reported the results and offered one problematic student outcome for faculty development during a responsive, all-faculty workshop of 28 participants. 


\section{Literature review}

In accord with the vision statements of some professional organizations and with recent research, writing program assessment has multi-purposeful and cyclical goals. Some goals are to report the assessment strategies and results to teachers so as to eventually facilitate students' learning (NTCE, 2004). Likewise, it is recommended that the faculty should cooperate in writing assessment to ensure that classroom instruction is interrelated among similar courses in the department (Association of Departments of English, 1993). When discussed cooperatively, writing assessment can ascribe agency to the instructors (Slevin, 2001, p. 293), initiate faculty development, and improve the curriculum as well as the program (Huot \& Schendel, 2002, pp. 207-208). Especially when adjunct or contingent instructors contribute to the program, faculty development activities based on assessment results in such venues as teaching workshops or grading sessions, provide some necessary tools for daily activities (Carpenter, 2002).

Common views on assessment practice advocate for a process that moves beyond the evaluator's reporting of facts during in-service training. For one, Guba and Lincoln have proposed a "responsive evaluation" in that the groups of stakeholders interact with other groups in a "hermeneutic dialectic" (1989, pp. 41-42) so that while concerns or answers may not reach a consensus, some conclusions are arrived at jointly. They define their approach as a "fourth generation evaluation" that, in part, uses the "claims, concerns, and issues of stakeholders ... as organized foci" (p. 50) to expose and recognize different positions (pp. 55-57) that could lead to greater knowledge and to possible 
action (pp. 67-73). Another view is from Davis et al. (1987) who assert that the unintended results that emerge from an in-service training sessions are often more important than the original goal, whether they include "cognitive skills, social skills (or) attitude changes" (p. 9).

As a part of some newer assessments, one important goal for a writing program has been to integrate the concept of critical thinking. Although defined variously (cf. Condon \& Kelly-Riley, 2004), "critical thinking" studies and tests continually add to methods that help the students develop their ideas beyond the superficial. For instance, Blattner and Frazier (2002, citing Ennis, 1993) affirmed that further purposes of critical thinking tests included "diagnosing strengths and weaknesses of students' critical thinking abilities, providing feedback to their students about their critical thinking skills, challenging students to improve their critical thinking abilities, and informing teachers about their students' critical thinking capabilities and how the instruction in their classrooms might have contributed to that development" (2000, pp. 2-3). In part, Blattner and Frazier affirmed that readers could evaluate students' critical thinking skills as derived from a performance-based test of an impromptu writing assignment, but that students needed to incorporate interpretations into their own essays (p. 10).

On testing critical thinking separately from good writing, Condon and Kelly-Riley (2004) argue that writing and critical thinking are not necessarily linked, but are "abstract, complex, socially constructed, (and) contextually situated terms" (p.7). "Good" writing, the authors propose, varies according to the discipline; "Critical thinking" even varies by the values and the types of work required in the discipline. Moreover, Condon and Kelly-Riley grant that 
maturation influences critical thinking (pp. 7-9) and affirm Haswell's (1991)

observation that when writers engage new ideas, their writing often breaks down

in structure. Writing itself, assert Condon and Kelly-Riley, can act as a

"vehicle" for critical thinking, but does not necessarily engage critical

thinking (p. 10).

Further, Condon and Kelly-Riley (2004) acknowledge problems with the assessment

of critical thought in writing. They advocate for finer assessments rather than holistic scoring that can disguise or overlook specific student problems ( $p$.

11). Additionally, they support the role of faculty, suggesting that promotion of critical thinking needs to be done overtly, using students' actual products since rapid improvement flows from clearer instruction about the evaluation criteria (p. 12). Condon and Kelly-Riley conclude that we check whether we actually promote the values and competencies we claim and whether the assessment tools actually test them (p. 12).

3. Our purposes and goals

Because the Writing Studies Program had retained PAS with established criteria that were calibrated, I collated the data to identify areas for student success. In short, the inductive research questions were the following:

1. Evaluative construct for assessing the research: What student outcomes in WTNG 100 and WTNG 102 showed strength and what could use improvement?

2. Formative construct for the workshop: How could the faculty facilitate improvements in students' writing in a workshop that engaged full-time and adjunct faculty interaction?

With the larger goals of informing the faculty about student outcomes and of affirming or realigning the Writing Studies Program' objectives, evaluations 
were conducted (2004-2006). In the preliminary study, the low grades of the less-prepared students in WTNG 100 (Spring 2004) were compared to those in WTNG 102 in the same semester. In a longer study, however, the A grades in both WTNG 100 and WTNG 102 (Fall 2004-Spring 2005-Fall 2005) were averaged separately to ascertain whether the same outcomes were equally problematic.

Finally, the Writing Studies Department faculty sponsored a Summer Workshop (2006) to share the data, to develop the full- and part-time faculty's teaching repertoire, to offer a venue for discussion of "Development" which was subsumed as critical thinking, and to evaluate the workshop itself. Thus, the workshop was poised to engage in an evaluation that was both "responsive" in that the faculty had long shown curiosity about the results of their PAS and was "emergent" in that they wanted to participate in the discussion of the data (Guba and Lincoln, 1987, pp. 38-39).

4. The workshop methods

The one-hour presentation was divided into several parts:

In Phase 1, the evaluator presented the data through a PowerPoint presentation of tables and asked for questions and comments from the faculty. In Phase 2, the evaluator pre-selected development as a focus, provided some sample methods to encourage student development of the essay, asked the audience to work in pairs on a sample essay, and facilitated a general discussion.

In Phase 3, the evaluator requested that the faculty evaluate the workshop by completing a comment sheet.

\subsection{Phase 1: Understanding the data}

First, the methods of assessing the portfolio outcomes were explained to the 28 faculty members attending. 
Methodology was straightforward. The numbers of grades for each outcome were

averaged by the number of grades submitted. Otherwise, when the number of grades in one category was fewer than the number of portfolios (in cases where the instructors neglected to complete the portfolio sheet), the average was determined by actual number of grades recorded. In the case of a split grade, such as an $A / B$, the lower of the two was used in the calculation because the curve was already biased towards higher grades since some disheartened students had neglected to submit their final portfolios. Results for WTNG 100 and WTNG 102 were calculated separately. Throughout the data analyses period, instructors varied somewhat (with the change of a few adjuncts, but retaining a consistent ratio of about $80 \%$ of the whole faculty). On the other hand, the placement procedures, the primary texts, and the Portfolio Grading Criteria remained constant.

Next, the faculty were shown the results of the Portfolio Assessment Outcomes via PowerPoint tables.

1. WTNG 100-Spring 04

In the small preliminary study in Spring 2004 on WTNG 100, 26 students' PAS indicated that out of the 10 criteria (see Appendix B) graded C- or NP, 7 students received low grades on Development, Sentence Awareness, and Grammar/Mechanics. The evaluator's initial concern was that more than one quarter or $27 \%$ of the students scored a C- or NP in lack of Development.

2. WTNG 102-Spring 04

In the larger study from the same semester on WTNG 102, the 174 students' grades on the seven criteria of the PAS (see Appendix B) showed that more than half (averaged as 58\%) of the C- and NP portfolios and $27 \%$ of the C grade 
portfolios scored low grades on Development.

\section{Comparison of PAS Outcomes during Fall 04 - Fall 05}

During the three semesters, decline in A grades for both courses was noted for the criterion of Development. WTNG 100's A grades were consistently less than $20 \%$ and generally lower than Sentence Awareness and Grammar; moreover, B grades declined steadily. At the same time, WTNG 102's A grades in Development fell from $42 \%$ to $18 \%$, while the NP grades increased from .08\% to $2 \%$.

\subsection{Phase 1: Faculty discussion of the data}

After the presentation of all the data from the PAS, the discussion began with faculty's questions about the methods and with general observations about the results. Most noted the general consistency in the three semester averages. Others commented with pleasure on the high grades for WTNG 100 and WTNG 102 that the students received in most categories (60-70\% earning A or B). That the group shared in most students' successes seemed to result in the faculty's attitude of satisfaction in their own instruction. The positive attitude affirmed that our faculty generally held a high sense of responsibility for the teaching of writing, for their agency in owning their courses, and in the writing program's quality (Slevin, 2001, p. 299).

However, the discussion then turned to negative interpretations when the faculty openly discussed portfolio grading in general. One faculty member expected these high grades to reflect the problem of grade inflation, an issue she was sensitive about, probably because it was discussed in a workshop several years earlier. Two others supported her discontent about grade inflation. In reply, a tenured faculty member affirmed that since the portfolio measures improvement after revision and editing, B grades were not necessarily problematic, and she 
reminded the other faculty that additional factors would determine the final grade. Quite a few faculty members voiced agreement with this position. However, as the later opinions on the Faculty Comments Sheet indicated, those three faculty members still maintained that grade inflation was problematic (see Appendix D). Their resistance may be understood, in part, by claiming their own position as "hard graders," a reputation they seem to value. Consequently, the dialogue resulted in an exchange of information about an issue that had been submerged for several years. Whereas the three faculty members did not change their mind, the debate did confirm what Davis, Scriven, and Thomas assert about in-service training sessions: unexpected results are often more important than the original goal $(1987$, p. 9) because long-standing issues are aired even though they may not be resolved.

In addition to the general grading of the portfolios, the changes in Grammar scores became a topic of concern. Many commented on WTNG 100's declining A grades in Grammar from 21\% to 16\% to 7\% (although WTNG 102's A averages did not corroborate the decline). Still, the results led to immediate complaints about incoming students' lack of grammatical skills. The open discussion of students' lack of preparation for college work soon digressed into a series of extreme examples. Since this kind of discussion is all-too familiar in chats among the faculty, it seemed that a public airing of the concern could at least defuse some of the discontent that had seemingly been contained. The problem with a complaint session, however, is that if too lengthy, the discussion devolves into student bashing, as had been noticed in prior workshops. Because the discussion offered no new information, the evaluator redirected the groups' focus on the student outcome of Development, a strategy of redirection approved by Guba and 
Lincoln whenever redundancy becomes a problem (1987, p. 207).

\subsection{Phase 2: The focus on development}

To prepare for the in-service part of the Summer Workshop, the evaluator pre-selected "Development" as the focus for a variety of reasons. In general, Development was singled out because it was common to both courses and was a topic more conducive to the format of a workshop since faculty tend to favor a combination of conceptual and skill-specific discussions. Then too, Development presented high stakes for the students, counting $15 \%$ of the total portfolio grade in WTNG 100, and even 30\% of the portfolio grade in WTNG 102 (see Appendix B for all percentages). Development was preferred, in part, because the Grammar/Mechanics and Sentence Structure categories required a different venue for faculty instruction, especially since the program encourages a variety of methods in teaching these skills. Furthermore, the topic was chosen to deter fixation on surface errors, such as grammar, although the concern emerged almost immediately during the data discussion.

Most importantly, Development (or lack of "critical thinking") was a recurring problem as had been reported anecdotally by the Writing Studies faculty and by the same faculty who also teach in the Core Program (General Education Program). Equally important, it was (wrongly or rightly) presumed that Development included those aspects of critical thinking that contributed to students' "good" writing and good grades. Although Development is defined differently on the separate PAS, the parameters seemed to correspond with thinking skills. Our PAS defines Development in WTNG 100 as occurring when "The writer develops ideas logically with key reasons, examples, and explanations." For WTNG 102, "Development of ideas" is defined as occurring when "The writer advances a 
credible, well-reasoned argument by providing sufficient support."

Therefore, the second intention of this workshop was for both full- and part-time faculty to work together on something specific rather than theoretical. The workshop aimed to encourage faculty to expand their strategies of essay development, to help student writers extend their ideas, and to offer a forum for faculty discussion about how the focus on Development could stimulate critical thinking.

4.4. Phase 2: Engaging faculty to help a student develop the essay

To begin the instructional phase of the hour-long workshop, the 28 participants were shown the current definitions of Development according to the programmatic guidelines and the respective weights in the final portfolio grade (see Appendix C).

This PowerPoint slide was followed by another that listed some Methods of Development as derived from WTNG 100's current text, The Bedford Handbook, and from WTNG 102's text, Writing Arguments. During the next $30 \mathrm{~min}$, the faculty received handouts of the same list of Methods of Development and a sample of a non-passing student essay. Participants were asked to work in pairs to single out the ways that the writer

"Harry" could further "develop" the essay. After 20 min, faculty were asked to share ideas and

insights with the group.

\subsection{Phase 3: Asking for feedback}

During the last $10 \mathrm{~min}$, the evaluator asked the faculty to complete a brief Faculty Comment Sheet to evaluate the presentation and to offer comments anonymously (see Appendix D). The results are included in the following discussion. 


\section{Discussion}

In the data analyses themselves, the Writing Studies Department's use of PAS offered some advantages for assessment of WTNG 100 and 102. Instead of basing evaluation on a student's single, timed impromptu essay as is sometimes customary (e.g., Blattner \& Frazier, 2002), the portfolio method that integrated revised and edited essays seemed more in line with the context of our program's goals. The portfolio letters included the students' awareness of multiple drafts to create a successful text (WPA, 2000) and explanations of their writing strategies; additionally, the portfolios themselves reveal evidence of multiple samples with different audiences (Murphy, 1999, p. 129). Moreover, the portfolio selections that were process-oriented and site specific (Huot, 1996, p. 561) already conformed to the program's goal to focus on argument. Further, instead of using a rubric, evaluating the actual criteria of the PAS allowed us to locate the student outcomes that needed improvement, a methodology also favored by Condon and Kelly-Riley (2004), and to discover that our students needed to incorporate interpretations into their essays, a problem similarly noted by Blattner and Frazier (2002, p. 10).

Through the series of studies and with an eye towards improvement, we gained an

overview of how the students in both WTNG 100 and WTNG 102 were faring in our first-year writing courses. In general, low-scoring WTNG 100 students, especially repeaters, grappled with a variety of problems although Grammar, Sentence Structure, and Development (27\%) were most frequent, yet no single factor determined whether a portfolio failed. The sole NP portfolio suggested that the program succeeded in retaining a student who had not met a significant percentage of the criteria. Next, when the data for WTNG 102 was examined, 
Development was problematic in $58 \%$ of the C- and NP portfolios and in $27 \%$ of the C grades, a rate that suggests that even the students who met the basic outcome also found this criterion challenging. Third, the longer study for both WTNG 100 and 102 now showed that even the top-scoring students had consistently low scores for Development. Hence, lack of Development continued to be a growing concern. Nonetheless, a couple of variables have to be taken into account: Failing students may have neglected to submit portfolios or may have retrieved them prior to collation of the data. While lack of Development did not alone determine whether the each portfolio passed, the results suggested re-dedication to this area for the faculty and for further study of the program.

At this point, it seemed advisable that the results be presented to the faculty in the Writing Studies' Summer Workshop (2006). However, sharing the data was not the sole purpose of the gathering. Instead, the writing program viewed itself as a "work in progress" that would sustain the faculty's intellectual interests through discussion (Slevin, 2001, p. 300). As Slevin posits, "organic" faculty development emerges from faculty conversations and collaborative work, by incorporating "critical inquiry, close study, constant review, and attention to consequences" (p. 301). Thus, an additional purpose of the workshop was to embrace the contingent faculty's sense of responsibility for and commitment to the program's quality (Slevin, 2001, pp. 299-304). Moreover, the workshop was open to alteration in faculty's "cognitive skills, social skills" or attitude changes (Davis, Scriven, \& Thomas, 1987, p. 9).

In keeping with the goal to engage contingent faculty in the assessment results, the workshop not only informed teachers about RWU's data analysis, but also included the specific formative objective to help "develop" the faculty's 
teaching repertoire in supporting the students' ability to integrate critical thinking in their writing (i.e., "develop" the essay) through a focus on Development. Other objectives were to offer a forum for discussion and then to encourage participants to comment on the data and on the presentation. In short, the workshop followed some good training practices, in presenting the theory, demonstrating it, providing practice, and asking for prompt feedback (Showers, Joyce, \& Bennett, 1987). Moreover, the evaluator hoped that the workshop would serve as a forum to "refine, change, or even reject" current beliefs (Guba \& Lincoln, 1989, p. 47).

In describing the results of the Summer Workshop, the evaluator located problems

in each phase and then reported on the faculty's insights and comments. The data elicited both positive and negative results, noteworthy for other program developers who initiate assessment and who include contingent faculty. It proved what Davis, Gross, and Scriven have noted: unintended side effectives are often more significant than the stated goals $(1987$, p. 9).

On the positive side, the Summer Workshop presentation did fulfill several objectives. It informed teachers (28 part- and full-time faculty attending or about $90 \%$ of the whole faculty) about the methods of the data collection and the resulting student outcomes (NTCE, 2004). In fact, many instructors felt pleased with their ability to help students achieve high grades in some outcomes. Moreover, the workshop succeeded in its specific formative objective to help "develop" the faculty's teaching repertoire with the aim of supporting the students' ability to integrate critical thinking into their writing. The workshop method stimulated faculty to collaborate on the enhancement of good teaching, to promote consistency of instruction (ADE, 1993), to facilitate 
discussion about the program and curricular issues (Huot \& Schendel, 2002), and to plan ahead for curricular changes (NTCE, 2004) so as to improve the program's quality (Slevin, 2001, p. 299).

The technique of including a piece of student writing for faculty review had several benefits. For one, the essay enlarged the assessment by taking multiple measures into account (Davis et al., 1987, p. 69). The strategy of allowing participants to examine what particular details the writer selected (Odell, 1999, p. 19) found favor with the audience. From the 18 Faculty Comment Sheets that addressed the topic of "Data Evaluation," 13 respondents indicated that understanding the data analysis was helpful; and of the 21 respondents to the question of focusing on one specific issue, 8 found it useful (Appendix D). Equally important, some long-submerged issues emerged during the discussion of the student essay and on the subsequent workshop evaluation sheets. After the reading of the student essay, the faculty discussion drew out the problems that the workshop's concentration on Development had intended to avoid. Quite a few adjunct faculty voiced concern about the writer's surface errors in grammar and sentence structure, and others criticized the essay's structure, the author's intent, inconsistencies in documentation, or the writing's vacuous content, the latter itself an aspect that the workshop intended to address through Development. Possibly, the comment about vacuous content proves Condon and Kelly-Riley's (2004) assertion that writing can act as a "vehicle" for critical thinking, but does not necessarily engage critical thinking (p. 10). In a larger sense, the negative criticisms revealed that disagreements could add to a dialectic's strengths since several positions are exposed and recognized, thus engaging pluralism (Guba \& Lincoln, 1989, pp. 55-57). 
In addition to the focus on surface errors, the particular sample student essay induced unexpected problems. Afterwards on the comment sheets, faculty suggested that the essay be better suited for the discussion, mentioning that "Harry's essay" be edited beforehand for surface errors, that an " $A$ " essay be shown for contrast, and that the parameters of the assignment be clearer. Nonetheless, the essay evaluation did inform teachers about one student's lack of Development or of critical thinking, an aspect they immediately distinguished and discussed. Then too, from a larger perspective, the comments pointed to a program need for future training sessions (Ennis, 1993 cited in Blattner and Frazier, 2003), perhaps a common grading session between adjunct and full-time faculty. Even if "cross-fertilization" ends in an incomplete consensus (Guba \& Lincoln, 1989, pp. 72-73), one benefit is that it can lead to new insights and activities.

Second, the faculty interpretation of the PAS criteria revealed problems about the concept of Development. Originally, the two definitions were predicated on the faculty's desire to lead students into thinking more deeply about their ideas and on the program's need to form a developmental sequence of increasing rigor and complexity. Colloquially, some instructors defined Development as simply, "I know it when I see it." Therefore, as Guba and Lincoln posit, to make sense of situations, people interpret experience both logically and intuitively (1989, p. 70) and both approaches are valid. Additionally, most faculty interpreted Development as a necessary aspect of or as akin to critical thinking skills. On the other hand, the definitions from the Portfolio Assessment Sheets appear to conflate writing and thinking, a problem if the two are better separated, as argued by Condon and Kelly-Riley (2004, p. 9).

Under "Concerns" of the Faculty Comment Sheets, a couple of respondents noted 
that the criteria of Support and Development are "confusing" — even to the instructors, but that "Development and Analysis go hand-in-hand" (see Appendix D). Clearly, the sample essay proved that the general-to-specific paragraph followed the structural prescription, but lacked what we might call Development or further ("critical") thinking. Thus, one of my claims that Development was problematic was affirmed in the workshop even though the definition was unclear.

In short, the faculty workshop concluded with more questions than answers. Locally, the Writing Studies Department must question whether our participatory-derived student outcome of Development implies or includes critical thinking. And, of course, larger questions emerge: What is critical thinking exactly? And, if we cannot define it, how can we measure it? Furthermore, even if we can define it, is it distinct from writing? Therefore, in a nod to the strategy of responsive evaluation, our discussions proved what Guba and Lincoln offer: that fourth generation evaluations often raise more questions than answers and often pause, not end (1989, p. 223).

In spite of the problems with the participants' focus, the definition of Development, and the potential conflation of good writing with critical thinking, the participants offered comments that indicated their knowledge of good writing practices. During the discussion, faculty generally agreed that good writing and critical thinking were socially constructed and contextually situated, as noted by Condon and Kelly-Riley (2004, p. 7). Some opined that methods of development hinged on the expectations of the assignment and on students' prior experience, general knowledge, and general values. In this way, the respondents illustrated an "ontological authenticity" (Guba \& Lincoln, 1989, p. 248) when they began to appreciate the Writing Program's objective to 
encourage students "to articulate critical analyses" and when they engaged in current pedagogical theory through the dialectic process (Guba \& Lincoln, 1989, pp. 42-44).

Moreover, the participants acknowledged verbally that in teaching the sequence of courses, they observed that maturation influences critical thinking, as Condon and Kelly-Riley affirmed (2004, p. 8). If nothing else, the faculty agreed that the students who enter WTNG 102 in the second semester from the WTNG 100 course in the fall show a better variety of thinking skills than those who do not. Several participants recognized empirically that grading first drafts was problematic since new ideas and new relationships among the ideas are often expressed illogically (see Haswell, 1991 cited in Condon \& Kelly-Riley, 2004, p. 9), but that revision helped clarify most students' thinking, especially cause-effect connections, again a probable aspect of critical thinking. Voiced by one participant as "Students need to dwell on thinking," but with tacit agreement from others, RWU writing instructors continually worry about how to get students to reflect upon their ideas, how to think more deeply, to think back towards the causes, or forward to the effects or consequences, or even how to understand unwritten assumptions. The general problem about contemplation seems to have multiple origins: from local circumstances, such the students' lack of reflective time during a busy school schedule, the need to achieve satisfactory grades in all courses, or simple maturation—to wider causes, such as parental demands for achievement, the administration's need to produce students as successful consumers of education, and the culture's emphasis on immediate gratification. Some writing instructors feel that even after a fruitful conversation with students during a conference, the students run off to 
other obligations and forget whatever constructive advice they have just acknowledged.

\section{Conclusion}

If the RWU Summer Workshop proved anything, it showed that instructors, like students, can be led to "methods" of development to encourage critical thinking, but that without quality time to think (perhaps even quality time alone)_participants (or students) may focus their attention on situational issues rather than upon enlargement of ideas. The workshop also suggested that the presentation was too ambitious: one hour was too short to accomplish everything. Perhaps one session should focus on the data and the next on a specific outcome.

At the very least, the 2006 Summer Workshop confirmed that one college's participatory exercise in improving writing found several unintended results. Some faculty persisted in claiming their position as rigorous graders in spite of conversations to the contrary. Other faculty members tended to belabor surface errors even though encouraged to focus otherwise. Most of the faculty agreed that the student outcome of "Development" as a synonym for critical thinking was problematic. Whereas Development intended to integrate critical thinking (itself problematic in definition), its discussion evoked a larger issue: Whether that particular outcome actually tested what was intended. The workshop subsequently affirmed what Condon and Kelly-Riley (2004) proposed: that we check whether we actually promote the values and competencies we claim and whether our assessment tools actually test them (p. 12). It appears that one problem with deriving student outcomes from on-site faculty participation is that the faculty must continue to agree on the meanings of each outcome. In 
addition, the workshop's unresolved issue of critical thinking now serves as a "placeholder" where compromise cannot be reached until further knowledge is forthcoming (Guba \& Lincoln, 1989, p. 223).

Altogether, reporting problems, concerns, and issues to the assessment community

at large may be just as important as recognizing successes: envisioning another writing program's "warts" may elicit better results from other assessment practitioners-if only to reassure them that unintended side-effects, while perhaps disconcerting at first, are equally valuable to a program's integrity, collegiality, cohesion, and improvement.

\section{References}

ADE, 1993 Association of Departments of English (ADE). (1993, March). Modern Language Association policy. Retrieved July 3, 2006, from

http://www.sciencedirect.com/science?_ob=RedirectURL\&_method=externObjLink\&_lo cator=url\&_plusSign=\%2B\&_targetURL=http\%253A\%252F\%252Fwww.mla.org\%252Fade\%2 52Fpolicy\%252Findex.htm.

Blattner and Frazier, 2002 N.H. Blattner and C.L. Frazier, Developing a performancebased assessment of students' critical thinking skills, Assessing riting 8 (1) (2002), pp. 4764. SummaryPlus | Full Text + Links I PDF (85 K) | View Record in Scopus I Cited By in Scopus (0)

Carpenter, 2002 W.J. Carpenter, Professional development for writing program staff. In: I. Ward and W.J. Carpenter, Editors, The Allyn \& Bacon sourcebook for writing program administrators, Longman, New York (2002), pp. 156-165.

Condon and Kelly-Riley, 2004 W. Condon and D. Kelly-Riley, Assessing and teaching what we value: The relationship between college-level writing and critical thinking abilities, Assessing Writing 9 (1) (2004), pp. 56-75. SummaryPlus I Full Text + Links I PDF (446 K) I View Record in Scopus I Cited By in Scopus (2)

Davis et al., 1987 B.G. Davis, M. Scriven and S. Thomas, The evaluation of composition instruction (2nd ed.), Teachers College Press, New York (1987).

Ennis, 1993 R.H. Ennis, Critical thinking assessment, Theory into Practice 32 (3) (1993), pp. 179-187. 
Guba and Lincoln, 1989 W.G. Guba and Y.S. Lincoln, Fourth generation evaluation, Sage, Newbury Park (1989).

Huot, 1996 B. Huot, Towards a new theory of writing assessment, College Composition and Communication 47 (4) (1996), pp. 549-565. Full Text via CrossRef

Huot and Schendel, 2002 B.A. Huot and E.E. Schendel, A working methodology of assessment for writing program administrators. In: I. Ward and W.J. Carpenter, Editors, The Allyn \& Bacon sourcebook for writing program administrators, Longman, New York (2002), pp. 207-227.

Murphy, 1999 S. Murphy, Assessing portfolios. In: C.R. Cooper and L. Odell, Editors, Evaluating writing: The role of teacher's knowledge about text, learning and culture, NTCE, Urbana, IL (1999), pp. 114-132.

NTCE, 2004 National Council of Teachers of English (NCTE). (2004, November). Framing statements on assessment. Revised report of the assessment and testing study group of the NCTE executive committee. Retrieved July 3, 2006, from

http://www.sciencedirect.com/science?_ob=RedirectURL\&_method=externObjLink\&_lo cator=url\&_plusSign=\%2B\&_targetURL=http\%253A\%252F\%252Fwww.ncte.org\%252Fabout \%252Fover\%252Fpositions\%252Flevel\%252Fcoll\%252F1 18875.htm.

Odell, 1999 L. Odell, Assessing thinking: glimpsing a mind at work. In: C.R. Cooper and L. Odell, Editors, Evaluating writing: The role of teacher's knowledge about text, learning and culture, NTCE, Urbana, IL (1999), pp. 7-22.

Roger Williams University, 2005 Roger Williams University, Department of Writing Studies. (2005). Retrieved July 31, 2006, from

http://www.sciencedirect.com/science?_ob=RedirectURL\&_method=externObjLink\&_lo cator=url\&_plusSign=\%2B\&_targetURL=http\%253A\%252F\%252Ffcas.rwu.edu\%252Fwriting $\% 252$ Findex.htm.

Showers et al., 1987 B. Showers, B. Joyce and B. Bennett, Synthesis of research on staff development: A framework for future study and state-of-the-art analysis, Educational Leadership 45 (3) (1987), pp. 77-87.

Slevin, 2001 J. Slevin, Engaging intellectual work: The faculty's role in assessment, College English 63 (3) (2001), pp. 285-305.

WPA, 2000 Writing Program Administrators (WPA). (2000, April). Outcomes statement for first-year composition. Retrieved June 30, 2006, from

http://www.sciencedirect.com/science?_ob=RedirectURL\&_method=externObjLink\&_lo cator=url\&_plusSign=\%2B\&_targetURL=http\%253A\%252F\%252Fwpacouncil.org\%252Fposit ions\%252Foutcomes.html.

Appendix A. RWU Writing Studies Department's Course Guide Descriptions and Objectives 
A. 1. Introduction to Academic Writing: WTNG 100

Course description

Focusing on the connection between reading and writing, this course emphasizes the development of sound academic arguments. In a series of increasingly more complex assignments students learn the rules of structure and grammar that govern academic writing. In addition, students learn the distinct purposes of summary and analysis. Assignments focus on how academically oriented texts construct an argument and on the role language plays in conveying the text's meaning. Students must write a series of compositions, pass a common grammar exam, submit a satisfactory portfolio, and earn a C- in the course in order to enroll in Expository Writing.

Course objectives

Students in WTNG 100 will be able to

- Summarize accurately

- Distinguish between summary and analysis

- Write thesis statements and topic sentences which establish and maintain the controlling idea

- Structure general-to-specific paragraphs

- Develop ideas logically with key reasons, examples, and explanations

- Organize ideas coherently

- Provide logical transitions within and between paragraphs

- Craft clear, concise, and varied sentences

- Show proficiency in applying the conventions of Standard Written English

- Write using a tone appropriate to audience and purpose.

A.2. Expository Writing: WTNG 102

Course description 
Expository Writing covers the rhetorical elements of sound argumentation.

Students learn how to write well-structured, well-developed essays that demonstrate a proficiency in standard written English. Assignments include close textual analysis of persuasive essays, rebuttal arguments, and position papers.

Students must pass a common grammar exam, submit a satisfactory portfolio, and earn a $\mathrm{C}$ - in the course in order to enroll in a 200-level writing course.

Course objectives

Students in WTNG 102 will be able to

-Write using a tone appropriate to audience and purpose

- Formulate a clearly focused thesis statement that provides essay unity

- Create a logical order of ideas

- Write a well-reasoned, well-supported coherently organized argument

- Quote, summarize, paraphrase and document accurately according to MLA guidelines

- Write demonstrating mastery of the rules that govern Standard Written

English

- Write demonstrating sophistication of ideas and expression.

Appendix B. Weights of Student Outcome Criteria from RWU's Portfolio Assessment Sheets

A. WTNG 100 Portfolio Criteria:

- Summary (5\%)

- Analysis (10\%)

- Controlling idea (15\%)

- Paragraph structure (10\%)

- Development (15\%) 
- Organization (10\%)

- Coherence (5\%)

- Sentence awareness (10\%)

- Grammar/mechanics (15\%)

- Tone (5\%)

B. WTNG 102 Portfolio Criteria

- Tone (5\%)

- Controlling idea (10\%)

- Organization and sequencing (10\%)

- Development (30\%)

- Integration of sources (10\%)

- Sentence structure/grammar/mechanics (30\%)

- Sophistication of ideas (5\%)

Appendix C. Weights of "Development" from Portfolio Assessment Sheet

1. WTNG 100: Introduction to Academic Writing

Development (15\%)

The writer develops ideas logically with key reasons, examples, and explanations.

ABCC-NP

2. WTNG 102: Expository Writing

Development of ideas (30\%)

The writer advances a credible, well-reasoned argument by providing sufficient support. ABCC-NP Appendix D. Selected Faculty Responses to "Development" Workshop (June 14, 2006) 
The faculty were encouraged to write comments on the three categories below. Of the 30 faculty who attended, 28 responded in writing to various parts of the questionnaire.

Faculty comments on assessment and presentation

1. Evaluation of data ( $n=21$, but with multiple responses)

a. Positive13

b. Negative4

c. No response4

d. Liked focus on one issue8

e. Grade inflation3

2. Concerns, comments, suggestions

a. Concerns

1. Questions "norming"

2. Development/Support are confusing

3. Development/Analysis go hand in hand

4. Flesh out differences between Explain/Develop ideas

5. Expository Writing sheet needs "address assignment" section

6. Students need to dwell on thinking

7. PIE (point-illustrate-explain) models mislead students into reliance on paradigms and stop thinking

b. Suggestions

1. Everyone assess a portfolio together

2. More than one example of a failing student paper/example of a passing paper

3. Share more assignments 
4. Session on conducting student conferences

5. Share other faculty's methods about effective strategies for

Development

6. Team grading

7. More discussion of Development/Extend "Development" to a subsequent session

3. Effectiveness of presentation

1. Short and to the point/helpful/worthwhile/productive/useful/interesting/effective/nicely facilitated/enjoyed open discussion/good/good slide design/good brevity/very good

2. Need clearer directions for group work

3. Use of student essay sample was effective/poor example

4. Samples of Development from texts was good

5. Applicable to Core 104 (other courses)

Tel.: +1 401254 3839; fax: +1 4011543845 .

Assessing Writing

Volume 12, Issue 3, 2007, Pages 199-212

Copyright @ 2008 Elsevier B.V. All rights reserved.

ScienceDirect $₫$ is a registered trademark of Elsevier B.V. 